REFLEXIÓN

Recibido: 25/10/2013

Revisado: 25/11/2013

Aprobado: 25/12/2013

\title{
LA RELACIÓN ENTRE DETERMINISMO GEOGRÁFICO Y RACISMO EN LA CIENCIA BRASILEÑA, FINALES XIX, PRINCIPIOS XX (REFLEXIÓNES A PARTIR DE PRETO NO BLANCO DE SKIDMORE)
}

\author{
PAUL SUTERMEISTER \\ Doctorando Literatura Latinoamericana. \\ Universidad de Zurich
}

\begin{abstract}
RESUMEN
Tentamos asignar al determinismo geográfico su debido lugar en la historia de las ideas del Brasil moderno: a partir de varios ejemplos tomados del clásico Preto no branco del brasilianista Thomas Skidmore demostramos una relación de complementariedad entre determinismo geográfico y racismo. Ambas doctrinas sirvieron a una élite intelectual brasileña para naturalizar retóricamente las desigualdades sociales $y$, de esta manera, para descartar ideas alternativas -históricas- que proyectaron una sociedad más justa para el Brasil.

Palabras clave: Historia de las ideas, Brasil, positivismo, determinismo geográfico, racismo.

ABSTRACT

We try to assign geographic determinism its proper place in the history of the ideas of modern Brazil: from several examples taken from the classic Black White by Brazilian scholar Thomas Skidmore we show a complementary relation between geographic determinism and racism. Both doctrines served a Brazilian intellectual elite to rhetorically naturalize social inequalities and, in this way, to discard alternative ideas - historical - that projected a more just society for Brazil.
\end{abstract}

Key words: History of ideas, Brazil, positivism, geographic determinism, racism.

Contra todos los importadores de conciencia enlatada. La existencia palpable de la vida. Y la mentalidad prelógica para que la estudie el señor Lévy-Bruhl.

Oswald de Andrade, Manifiesto antropófago, 1928

La "fe en la ciencia" es una categoría fundamental para comprender la modernidad. Un ejemplo que salta a la vista: el historiador de la ciencia estadouni- dense Robert Proctor nos enseña que las ciencias, la antropología en particular, practicadas bajo los nacional-socialistas, eran ciencia en el propio significado del término - no eran falsa conciencia:

En la teoría social liberal, la presunción en la mayor parte de este siglo ha sido o bien que la ciencia sea intrínsecamente democrática (es decir, que dependa y contribuya a formaciones políticas 
democráticas), o bien que sea apolítica, y que la politización de la ciencia implicaría su destrucción. [...] Implícito en este modelo es la concepción de que la ciencia no pueda florecer en una sociedad que requiere que la ciencia no sirva a intereses ajenos a ella misma. También hay una política implícita en este juicio: esto es, que la ciencia crezca sólo en el terreno de la democracia, y que fuerzas sociales que son hostiles a la democracia sean hostiles a la ciencia. Tal punto de vista sostiene que el destino de la ciencia en un régimen totalitario es que va a ser suprimida: la posibilidad de que la ciencia (o los científicos) podría contribuir a movimientos fascistas es totalmente descartada [...] Dado tal punto de vista, no es difícil entender por qué los filósofos han fracasado en general en comprender la ciencia bajo el fascismo: los filósofos en general han asumido que no podía haber nada digno de ser llamado 'ciencia' bajo los nazis. (Proctor apud Benoît Massin, capítulo 1 en: KAUPEN-HAAS; SALLER (org.), 1999, p. 12-13; traducción y subrayado son nuestros)

Los efectos de la fe en la ciencia en el Brasil eran más sutiles que en el caso nazista; sugiero que este hecho hizo que ella perduró allí más que en Alemania, en forma de determinismos ambientales y en nuevas formas de discriminación social discriminadora. ${ }^{1}$ Los dos determinismos -el ambiental y el racial- forjaron elementos de identidad nacional que unificaron al mayor país de América Latina, eliminando fuerzas centrífugas (por ejemplo separatismos) $\mathrm{y}$ perpetuando malestares sociales. El

1. En lo que concierne a la actualidad de determinismos geográficos, concibo este trabajo como una introducción posible a mi tesis de maestría (São Paulo, 2011), introducción realizada con tres años de retraso desde que recibí sugerencias instructivas del Prof. Antonio Carlos Robert Moraes durante mi exame de qualificação, 17 de marzo 2010 en la FFLCH-USP. racismo, primero, lideró los discursos nacionales a través de la ideología de la esclavitud y del blanqueamiento; el determinismo geográfico sucedió al racismo como explicador natural de desigualdades sociales en el Brasil: discursivamente, el nordeste se tornaría pobre por su esencia tropical, y el sudeste se tornaría rico por su proximidad al clima europeo. Todo esto aconteció en un marco estricto de cientificidad, principalmente en Facultades de Medicina y Derecho (sobretodo en São Paulo, Río de Janeiro, Salvador, Recife y Belém; instituciones analizadas por SCHWARCZ, 1993).

Conocemos esta cientificidad bajo el rótulo del positivismo cuyo famoso lema "Orden y progreso" adorna la bandera del Brasil. El positivismo, fundado originalmente por el sociólogo francés Auguste Comte, representa tanto una filosofía del conocimiento -la fe en que todo sea explicable objetivamente- como una religión. Esta religión, "cuyo dogma es la ciencia y cuyo culto el arte", 2 y donde se venera a figuras como Galilei, Descartes o Darwin, cuenta hoy todavía con templos en el Brasil. Más que la historia de la iglesia positivista en el Brasil, me interesa el positivismo como filosofía del conocimiento -o como fe en la ciencia- que tiene todavía hoy una gran repercusión.

Lo novedoso de la presente ponencia debe ser el siguiente conocimiento: en la historia del pensamiento moderno brasileño, a diferencia de lo comúnmente pensado, la relación entre racis-

2. Como leemos en la página Web del Templo Positivista de la ciudad de Porto Alegre: http://positivismors. blogspot.ch/ 
mo científico y determinismo geográfico ${ }^{3}$ no es alternativa sino complementar. Ambas corrientes evocan una instancia suprahumana como decisora sobre el destino de los seres o sociedades humanos: tanto la clasificación biológica de si mismo como la clasificación ecoesférica de donde uno vive (cf. URTEAGA, 1993) escapa a la libre decisión del individuo: él no puede alterar ni su supuesta herencia genética ni su hábitat, a menos que -si uno piensa ambos determinismos hasta sus últimas consecuencias- substituya su ADN por otro, o se cambie de su tierra.

Pero la ingeniería moderna logró superar estas instancias suprahumanas: los nazis con su eugenesia y eutanasia, por un lado, y con su "etnomorfosis" (o "inversión étnica" forzada, genocidaria; ideología del Lebensraum) por otro lado, practicaron lo que una gran parte de cientistas de la época -parte de la élite ilustrada del Brasil, como veremosse atrevió a pensar apenas en teoría (recordemos que en tierras americanas a finales del siglo XIX, el mayor genocidio ya había pasado). La cuestión de lo que era primero, la teoría o la práctica, parece como aporía: ¿Era necesario que alguien piense primero las atrocidades para que después puedan ser llevadas a cabo? ¿O era, inversamente, primero la práctica de cuya experiencia se pudo desarrollar la teoría acerca de ella? Este dilema lo dejamos en el aire en esta ponencia; otro enfoque menos ético nos interesa más: para Michel Foucault, el desafío no consistiría tanto en juzgar el pensamiento de estos cientistas sino en descubrir cómo ellos llegaron a plantear los problemas descabellados que plan-

3. También llamable geograficismo científico. tearon. Focalizamos en la relación entre determinismo geográfico y racismo, dando un nuevo peso al primero relacionándolo con algo tan grave como el segundo. Ya no se podrá decir que el determinismo ambiental sea mero sentido común o un simple mito ${ }^{4}$; le quitamos la ingenuidad al determinismo geográfico. Ambos determinismos son dos caras de una misma moneda. La relación entre geodeterminismo y determinismo racial fue discutido por numerosos y eminentes pensadores, sobretodo por el sociólogo brasileño Gilberto Freyre que escribió en 1933 en su Casa grande y senzala (1977, p. 60):

[...] se condena a muerte al brasileño porque es mestizo y al Brasil porque se encuentra, en gran parte, en zona de clima cálido. Poco o ningún caso ha prestado esa sociología, más alarmada con las manchas de mestización que con las de la sifilización, más preocupada con los efectos del clima que con los de causas sociales $[\ldots]$

Esa doble estigmatización denunciada por Freyre es nada diferente de lo que describimos en un párrafo anterior: contra tales juicios, el brasileño no pudo defenderse sin cambiar su "raza" o su "tierra". Y la ciencia sociológica - las ciencias brasileñas más diversas, como veremos - sustentó estas estigmatizacio-

4. Mitos del tipo "dans les climats chauds [...] les passions se font plus tôt sentir" (Montesquieu; cf. URTEAGA, 1993). Traducida al lenguaje del desarrollismo moderno con su insoluble abstracción -véase mi tesis de maestría-, esta frase quiere decir grosso modo: el clima en cuanto procesos meteorológicos que tienen lugar en la atmósfera de nuestro planeta, es la causa de que algunos seres humanos sean más pasionales, que por su vez significa menos racionales; así se tornaría -para los que dan fe a ese tipo de cortocircuitos intelectuales- más comprensible por qué unos sean más pobres que otros (correspondiente al título de un libro más que discutible del historiador estadounidense David Landes que utilicé en mi tesis de maestría) - es lo que quiero comprender como naturalización de la desigualdad. 
nes, como lo acusa Freyre. Una cuestión es: ¿Por qué tantos cientistas republicanos, médicos, abogados e ingenieros entraron en este pantano filosófico de los determinismos, y qué fue lo que les permitió o prohibió de salir de él? Pues: ¿Cuántos cientistas estaban prisioneros en las ciencias naturales, sin ver alternativas humanas? Surge una pregunta que va, talvez, demasiado lejos: ¿Por qué la élite ilustrada brasileña era ciega frente a teorías sociales de Marx, Nietzsche o Freud, teorías cuya esencia sea lo profundamente humano, y que los hubiera sacado tranquilamente de los pantanos del positivismo, del naturalismo? (¿Era naturalmente necesario esperar otro medio siglo para que los espíritus intelectuales maduren?)

El propio Freyre era, en gran parte, prisionero de estos pantanos: lo demuestra en sus innumeras referencias a cientistas naturales, refiriéndose a ellos como en un movimiento circular para refutarlos con sus propios métodos científicos naturales. En Casa grande y senzala, Freyre (Op. cit.) reflexionó "científicamente" sobre los brasileños y el Brasil, considerado por él la "civilización principal moderna de los trópicos"; reflexionó sobre el "clima", las "condiciones de vida en las zonas tropicales", la "cultura agraria tropical del negro", el "carácter oceánico de Portugal"; sobre "raza y clima", entre otras cosas 5 .

Volvamos a la cita de Freyre arriba: esta conciencia que él invoca, "de teorías científicas que han prestado poco o ningún caso", es típica para toda una época cuya particularidad es la fe en cierta ciencia importada (o enlatada, como dice el lema que escogí para esta ponencia)

5. Lemas tomados del índice remisivo de la edición portuguesa publicada por la Global Editora (São Paulo, 2003), en función de su relación con el tema de esta ponencia. de Europa. Para un breve recorrido de esta época basémonos en un clásico sobre el asunto: Preto no branco: raça e nacionalidade no pensamento brasileiro, libro que discute los discursos sobre la "raza" en el Brasil de finales del siglo XIX a inicios del siglo XX, publicado en 1974 por el historiador estadounidense Thomas Skidmore $(2012)^{6}$. Las dos categorías de esta fe invocadas por Freyre, el racismo científico y el determinismo geográfico, se complementaron en la construcción de nación en el Brasil; ambos se basaron en ciencias naturales de la época y tuvieron su auge entre 1870 y 1930. Generaciones de científicos y políticos brasileños, de la Escuela del Recife a partir de 1870 hasta los años treinta - el político y crítico literario brasileño Silvio Romero (1851-1914), el abogado y crítico literario Araripe Júnior (1848-1911), el ingeniero y escritor Euclides da Cunha (1866-1909), el médico, crítico literario y político Afrânio Peixoto (1876-1947), todos ellos miembros de la Academia Brasileña de Letras, y muchos otros negociaron argumentos de la "raza" a cambio de argumentos del "clima" y viceversa, gastaron energía en miles de hojas de libros y revistas científicos para debates que hoy parecen, en gran parte, caducos o repugnantes (en términos de historia de las ideas científicas) - aparte del valor estético de su obra literaria - , si no darían material para comprender una parte ideológica de la modernidad brasileña, el enfoque del que me apropio en mi proyecto de doctorado. Se basaron en ciencia que proyectó que los europeos tuvieran que "racialmente" revalorizar los países cálidos y tropicales por medio de su conquista e inmigración, países que, no obstante, debido a su clima

6. Skidmore dedica el libro a la pregunta - y sobre todo a sus respuestas - si es correcto que el progreso moderno solo seria destinado a "varones blancos de zonas templadas" (2012, p. 32). 
quedarían por siempre "inferiores" a los de Europa y Norteamérica. "La cuestión de la raza (y las cuestiones correlatas del determinismo climático) estaba [...] siendo debatida abiertamente en Europa, y los europeos no titubeaban en expresarse en términos nada lisonjeros en relación a América Latina" (SKIDMORE, 2012, p. 31).

"Se afirmaba que los europeos del norte habían conquistado poder económico y político gracias a su herencia genética y al ambiente físico singularmente favorable. En suma, los europeos del norte eran las razas "superiores" y disfrutaban de un clima "ideal"; por implicación, las razas más morenas y los climas tropicales jamás podrían producir civilizaciones comparables. Algunos de esos autores excluían explícitamente la posibilidad de civilización en un área destituida de condiciones europeas. No por coincidencia, el análisis era dirigido a las áreas que habían sucumbido a la conquista europea desde el siglo XV: África y América Latina. Así, una Europa en expansión encontró una explicación científica para sus conquistas políticas y económicas" (SKIDMORE, Op. cit., p. 67).

Fueron europeos como Gobineau, Buckle, Taine o Haeckel ${ }^{7}$ que ejercieron, a través de su determinismo racial y ambiental, una fuerte influencia sobre la construcción de nación en el Brasil. De Taine provenía la idea de que todas las naciones se originen en su "raza, medio y momento"; de Buckle provenía la idea de que la naturaleza del Brasil

7. Joseph Arthur de Gobineau (1816-1882) fue un racista francés cuyas teorías influenciaron posteriormente el nazismo. Henry Thomas Buckle (1821-1862) fue un historiador inglés y autor de una inacabada Historia de la Civilización en Inglaterra en la cual menospreció al Brasil por su "naturaleza abundante". Hippolyte Taine (1828-1893) fue un naturalista francés que determinó la cultura literaria de un pueblo como resultado de su race, su milieu en que vive, y su moment histórico. Ernst Haeckel (1834-1919) fue el principal teórico alemán del darwinismo social. sea tan abundante que no deje suficiente espacio para que el ser humano pueda fundar allí una civilización propia.8 "Los brasileños leían esos autores, en general sin espíritu crítico, y su preocupación crecía" (SKIDMORE, Op. cit., p. 31). Partiendo de la elite intelectual brasileña de la época (ibídem, p. 299), Thomas Skidmore nos ofrece en su Preto no blanco, más allá de las figuras ya mencionadas, un catálogo (disperso) de autores brasileños que se ocupaban de la relación entre raza y clima. Siguen ahora, para el resto de la ponencia, trechos que esbozan la línea de este pensamiento, basados en una lectura exhaustiva de Preto no branco.

"Caudatarios de aquella cultura e imitadores constrangidos de aquel pensamiento, los brasileños de mediados del siglo XIX, como los demás latinoamericanos, estaban despreparados para discutir las últimas doctrinas sociales que llegaban de Europa" (ibídem, p. 31). Podemos discordar de Skidmore, pues un análisis más profundo de los textos correspondientes brasileños puede revelar que están no solo al mismo nivel sino que desafían con respuestas creativas a los provocadores europeos.

Una de las figuras brasileñas más conocidas por relacionar "raza" y "clima" fue el ya mencionado Silvio Romero, un "reformador liberal que se empeñó honesta y continuamente en cuestiones de raza y medio ambiente" (ibódem, p. 73). Skidmore trata a Romero sobre la base de las categorías racial y determinista climático y demuestra la complementariedad de esas dos categorías. En la obra História da literatura brasileira de 1888, año de abolición de la esclavitud en

8. La subsección sobre "el pensamiento europeo y dilemas deterministas" en Preto no branco de Skidmore (2012, pp. 66-72) describe breve pero concisamente el entrelazamiento de las ideas deterministas racistas y climáticas de los pensadores europeos de la época. 
Brasil, Silvio Romero hacía "un abordaje sociológico de la literatura, argumentando que la raza y el medio ambiente" -de cierta manera como ya lo hicieron Taine y otros para literaturas europeas- "eran vitales para la comprensión de las creaciones artísticas", con base en gran parte en el social Darwinista Herbert Spencer (ibídem, p. 73). "Partía del principio de que cualquier nación es producto de una interacción entre la población y su hábitat natural" (ibídem, p. 74). "Romero abordó de frente la cuestión del determinismo ambiental, calificando el veredicto de Buckle sobre Brasil como 'palabras duras, pero, en el fondo, correctas"” (ídem); recordamos que Buckle dividió "la civilización en dos grandes ramos: lo de Europa, y lo de fuera de ella; en el primero, predomina el esfuerzo del hombre sobre la naturaleza; en el otro, es lo contrario que se nota" (Romero apud SKIDMORE, Op. cit., p. 74). "Sílvio Romero no dudaba que el hábitat brasileño fuera seriamente debilitante. El calor opresivo y la sequía periódica contribuían para hacer el brasileño 'indiferente y apático”' (ibídem, pp. 74-75). Con su disposición a participar en los debates racistas e deterministas-climáticos, Romero se convirtió en protagonista de controversias en las cuales participaron innumerosos otros intelectuales de la época. Skidmore demuestra como los debates sobre raza y clima se intensificaron después de 1888, año de la abolición de la esclavitud en el Brasil. El teórico literario brasileño Roberto Ventura (1991), estudioso de las polémicas literarias entre 1870 y 1914, comienza con una discusión de las cuestiones clave raza, geografía y clima en el pensamiento brasileño, para después centrarse en las muchas "batallas" en que Sílvio Romero defendió sus ideas acerca de la identidad cultural de Brasil (VENTURA, 1991, pp. 17-43). Miguel Calmon elogió en 1922 “el 'elemento nativo' que contribuyó con el 'intransigente espíritu de apego al suelo' que daba a Brasil condiciones de 'repeler invasiones consecutivas' y "nos permitió afrentar y transformar una naturaleza tropical tan poco clemente"' (SKIDMORE, Op. cit., p. 233s).

También hubo lo inverso: un determinismo geográfico positivo: elogios a "los recursos naturales, el clima y el inmenso territorio de Brasil" (cf. SKIDMORE, ibídem, p. 328). Afrânio Peixoto, profesor de higiene en la facultad de medicina de Río de Janeiro, luchó "contra la teoría de los "trópicos insalubres" (ibídem, p. 257); en 1916 publicó Minha terra e minha gente, "el primer libro didáctico a abordar al mismo tiempo los problemas de la raza y del clima"; el determinismo climático le pareció más fácil para refutar que el racismo científico; enfermedades supuestamente tropicales como la fiebre amarilla, el paludismo, la anquilostomiasis y otras "no son peculiares a ningún clima sino a aquellas regiones cuyos habitantes no saben o no pueden combatirlas", como Peixoto escribió (ibídem, p. 238s). Su mensaje en defensa del clima brasileño "fue distribuido a generaciones de estudiantes de medicina en Río de Janeiro" (ibídem, p. 354$)^{9}$.

Como nos sugiere Skidmore (ibídem, passim), además de los ya mencionados, están a la espera de análisis más minuciosos las contribuciones al debate entre determinismo geográfico y racismo: del fundador de la Escuela de Recife Tobias Barreto (1839-1889); del jurista y historiador Clovis Bevilaqua (1859-1944); del jurista, escritor y político José Vieira Couto de Magalhães (1837-1898); del jurista, escritor y político Alfonso Celso de Assis Figueiredo Júnior (1860-1938); del jurista, escritor y político Gilberto

9. Para otros autores que "defienden el clima brasileño" véase también Skidmore, 2012, p. 336. 
Amado (1887-1969) y del crítico literario Grieco Agripino (1888-1973).)

El ensayista pernambucano José María Bello, por su vez, dio, según Skidmore (Op. cit., p. 240) "uno de los diagnósticos más clarividentes":

Alegamos cuestiones de raza, de clima y de momento histórico para justificar nuestra debilidad. Todas esas frases pomposas de una filosofía apenas asimilada pasaron, felizmente, de moda. Ni la raza, ni el clima tienen influencia decisiva en el desarrollo de un país. En condiciones normales de salud y de instrucción, valemos tanto cuanto cualquier otro pueblo (Bello apud SKIDMORE, Op. cit., p. 240).

Basílio de Magalhães, por su vez, "escribía libros didácticos de historia y geografía para uso en São Paulo, pero sus conferencias fueron extraordinariamente explícitas en el rechazo tanto de la raza cuanto del clima como explicación para el hecho de Brasil ser 'el grande enfermo de América del Sur"' (ibídem, p. 234).

Disidentes destacados, por lo que rechazan el cuadro de referencia común, son, según Skidmore, el médico y historiador brasileño Manoel Bomfim (18681932) y el abogado, político y periodista brasileño Alberto Torres (1865-1917) (ibídem, pp. 171-184). El médico legista y escritor brasileño "Roquette-Pinto seguía directamente los pasos de Manuel Bomfim y Alberto Torres al repudiar el cuadro de referencia racista y dar destaque a la reacción del hombre al medio ambiente como la variable fundamental" (ibídem, p. 264). Cada uno de estos autores tiene sus ambigüedades y debe ser analizado en el contexto de su época.

Estos disidentes demuestran que los ejemplos inquietantes más arriba mencionados no quieren
Decir que los determinismos raciales y climáticos fueran aceptados por todos los brasileños. Sería más correcto decir que mucha gente los aceptaba de modo tácito, mientras otros asumían implícitamente su posible validez. [...] Sus tesis presagiaron los dolorosos dilemas que formarían la mayor parte de la vida intelectual brasileña en las décadas que siguieron a la Abolición [de la esclavitud en 1888] (SKIDMORE, 2012, p. 31).

Concluimos con una línea general de la historia brasileña de las ideas científicas: entre 1870 y 1930 aconteció una substitución lógica del racismo científico por el determinismo climático. Mientras que el racismo se descalificó paulatinamente así mismo - por la genética moderna y por las experiencias genocidarias del siglo XX a niveles distintos - o fue substituido por formas más sutiles, el determinismo geográfico persiste en parte hasta hoy (como mostré en mi tesis de maestría). ¿Por qué el determinismo siguió el racismo y sobrevivió hasta la actualidad? Tal vez la "influencia del clima en los seres humanos" en la historia brasileña de ideas era más difícil de refutar que los argumentos racistas (que se desacreditaron a si mismos por el progreso de las ciencias biológicas); por otra parte, era tal vez más fácil apropiarse del argumento del milieu que del argumento del moment, de la "situación histórica", cuyo abordaje podía llevar consigo complicaciones políticas. (Pues un abordaje histórico de malestares políticos implicaría el reconocimiento de errores humanos en la gestión del Estado por la élite.) La historia de las ideas sugiere que el determinismo climático substituyó al racismo que -refutado por la biología moderna- dejó de servir para la naturalización de las desigualdades sociales.

¿Como seguir la investigación? Los discursos médicos, políticos y jurídicos más importantes del Brasil a finales del 
siglo XIX son ampliamente descritos en literatura secundaria tal como se ve en numerosas biografías sobre el abogado Silvio Romero o sobre los médicos Oswaldo Cruz y Afrânio Peixoto. Sin embargo, este camino extraño (planteado en el párrafo anterior) por el cual pasaron estos discursos todavía no se ha considerado en su conjunto: los escritos epistemolátricos focalizados aquí crearon, básicamente, una secuencia lógica herencia genética $\rightarrow$ medio ambiente $\rightarrow$ situación histórica (que nos recuerda, tal vez esforzadamente, la tríade de Taine "raza $\rightarrow$ clima $\rightarrow$ historia"), en la cual un argumento más simple está siendo gradualmente substituido por otro argumento más complejo. ¿Qué otros tipos de causalidades fueron ignorados, o excluidos del mundo de lo pensable, a través del determinismo geográfico-climático por los autores en cuestión? Tal vez la literatura secundaria sobre la "experiencia epistemológica nazista" nos pueda ofrecer herramientas para comprender mejor la evolución de las ideas en el Brasil entre 1870 y 1930 (como sugiero al inicio de la ponencia). Para solo mencionar un ejemplo de discursos excluidos: el materialismo histórico es una de las formas alternativas de explicación para desigualdades sociales -vía escogida por el historiador, geógrafo, escritor y político Caio Prado Junior (1907-1990) y por el sociólogo y político Florestan Fernandes (1920-1995)- que sigue siendo excluido por los determinismos en cuestión; su exclusión tal vez sea un objetivo deliberado de los deterministas geograficistas todavía hoy (me remito al capítulo 3, Anotações céticas, de mi tesis de maestría).

\section{BIBLIOGRAFÍA}

FREYRE, Gilberto. Casa grande \& senzala. Caracas: Ayacucho, 1977 (Primera edición de 1933).

KAUPEN-HAAS, Heidrun; SALLER, Christian (org.) Wissenschaftlicher Rassismus: Analysen einer Kontinuität in den Humanwissenschaften. Frankfurt/Nueva York: Campus, 1999.

SKIDMORE, Thomas E. Preto no branco: raça e nacionalidade no pensamento brasileiro. São Paulo: Companhia das Letras, 2012.

SCHWARCZ, Lilia Moritz. O espetáculo das raças. São Paulo: Companhia das Letras, 1993.

STEPAN, Nancy. Gênese e evolução da ciência brasileira. Rio de Janeiro: Artenova, 1976.

URTEAGA, Luis. La teoría de los climas y los orígenes del ambientalismo. En: Geocrítica: cuadernos críticos de geografía humana. Año XVIII, no. 99, noviembre de 1993.

VENTURA, Roberto. Estilo tropical: história cultural e polêmicas literárias no Brasil, 1870-1914. São Paulo: Companhia das Letras, 1991. 